Al-Kimia, 8-1-2020, 1-9

Available online at: http://journal.uin-alauddin.ac.id/index.php/al-kimia

\title{
The Carbon Effect in Biodiesel Synthesis
}

\section{Mohammad Arfi Setiawan*, Brilian Gema Morentera}

Department of Chemical Engineering, Universitas PGRI Madiun

*Corresponding Author: marfis@yahoo.com

Received: November,16,2018 /Accepted: June,06,2020 doi: $10.24252 /$ al-kimiav8i1.6368

\begin{abstract}
Biodiesel is synthesized from the trans-esterification reaction of vegetable oil and alcohol using a catalyst such as acids, bases or enzymes. The acid catalyst that is often used is sulfuric acid; $\mathrm{H}_{2} \mathrm{SO}_{4}$, and $\mathrm{HCl}$ while most of base catalysts are $\mathrm{NaOH}$ and $\mathrm{KOH}$. The aim of this study is to determine the effect of carbon derived from sugar heating in the synthesis of biodiesel with a sulfuric acid catalyst; $\mathrm{H}_{2} \mathrm{SO}_{4}$. Trans-esterification reaction of Jatropha oil and methanol with sulfuric acid catalyst was done with oil and methanol at 1:9 ratio. The results showed that (1) the physical properties of the biodiesel was synthesized with carbon- $\mathrm{H}_{2} \mathrm{SO}_{4}$ has a difference with physical properties the biodiesel was synthesized by sulfuric acid (2) carbon- $\mathrm{H}_{2} \mathrm{SO}_{4}$ was used in the transesterification reaction of Jatropha oil and methanol to produce methyl ester character is the density of $0.889 \mathrm{~g} / \mathrm{mL}, 24.59 \mathrm{cSt}$ viscosity and refractive index of 1.464, (3) methyl ester produced from the reaction of trans-esterification of Jatropha oil and methanol with sulfuric acid catalyst has a character that is a density of $0.882 \mathrm{~g} / \mathrm{mL}, 11.70 \mathrm{cSt}$ viscosity and refractive index of 1.458.
\end{abstract}

Keywords: biodiesel, carbon, jatropha oil, sugar, trans-esterification

\section{INTRODUCTION}

Biofuels are substances produced from biomass, serve as a source of renewable energy, and reducing $\mathrm{CO}_{2}$ production. The two most common types of biofuels in use today are bioethanol and biodiesel. Biodiesel is synthesized by trans-esterification reaction of oil and alcohol. The process often uses a basic catalyst because the reaction is faster than the acid catalyst. But the basic catalyst has a disadvantage because the presence of water and free fatty acids will form soap hence reduce the results. So, the availability of water and the amount of free fatty acids must be considered (Fukuda et al., 2001). Before the transesterification reaction should be conducted prior oil preparation that reduces free fatty acid with esterification reaction. To avoid the formation of soap, acid catalyst should be used.

Acid catalysts, based on their forms, are divided into homogeneous catalysts and heterogeneous catalysts. For acid-catalyzed systems, sulfuric acid has been the most investigated catalyst, but other acids, such as $\mathrm{HCl}, \mathrm{BF}_{3}, \mathrm{H}_{3} \mathrm{PO}_{4}$, and organic sulfonic acids, have also been used by different researchers (Lotero et al., 2005). The use of homogeneous catalysts in the synthesis of biodiesel has drawbacks since it is difficult to separate the products and the catalyst cannot be reused (Vasudevan and Briggs, 2008 and Zong et al., 2007). These drawbacks can be overcame by using heterogeneous acid catalysts. Thushari 
and Babel (2018) used coconut meal residue to made sulfonated carbon catalyst and employed it for the biodiesel production. Shu et al (2009) studied carbon based solid acid catalyst for transesterification of cotton seed oil with methanol.Sugar catalyst is a heterogeneous acid catalyst that has many advantages over other catalysts. According to Toda et al. (2005) sugar catalyst is more effective and environmentally friendly than other catalysts. Zong et al. (2007), performing esterification of oleic acid, palmitic acid and stearic acid with methanol using a catalyst sugar, stated that the sugar catalyst have a high effectiveness, low pollution, and can be reused and hence is suitable for the production of biodiesel

Sugar catalyst is made by heating sugar at $400^{\circ} \mathrm{C}$ with $\mathrm{N}_{2}$ flow to obtain the carbon. Heating sugars to $400{ }^{\circ} \mathrm{C}$ will evaporate the water but does not remove all oxygen atoms in the sugar so the sugar can be sulfonated (Okamura et al., 2006). In the existing studies, sulfonated carbon precursors was made with concentrated sulfuric acid or fuming sulfuric acid at high temperature (Santos et al., 2015; Tamborini et al., 2019; Zhang et al., 2017). Ramírez-Arias et al (2017) had synthesized biodiesel with activated carbon that presented 95$96 \%$ yield. The process can be seen in figure 1.

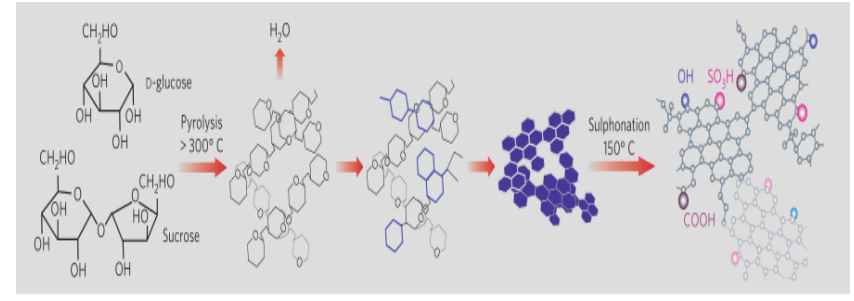

Figure 1. The Stage of Preparation Sugar Catalyst (Toda et al., 2005)

This study was conducted to determine the effect $\mathrm{N}_{2}$ flow in pyrolysis of sugar and the effect of carbon that produce from heating sugar without $\mathrm{N}_{2}$ flow in the transesterification reaction. Biodiesel synthesis methods have been developed, starting from the conventional method that is reflux, using microwaves to using ultrasonic waves. The conventional method is a common way to synthesize biodiesel. Biodiesel synthesis using microwaves like Sherbiny et al. (2010) and ultrasonic waves like Subhedar \& Gogate (2016) is a method that is being developed. In this study biodiesel was synthesized by conventional method using reflux.

\section{RESEARCH METHOD}

\section{Material and Tools}

Materials in this research are sugar, $\mathrm{H}_{2} \mathrm{SO}_{4}$, Jatropha oil, and methanol. Instrument used are furnace, three-neck flask reflux, centrifuge, Ostwald viscometer, Abbe refractometer, picnometer and GC-MS.

\section{Procedures}

\section{Carbon preparation}

10 grams of sugar (sucrose) in crusible is heated in the furnace at $\pm 400{ }^{\circ} \mathrm{C}$ for 17 hours. After 17 hours, the results is transferred into a beaker and concentrated sulfuric acid is 
added to the beaker containing the results of the furnace and heated to $\pm 150^{\circ} \mathrm{C}$ for 6 hours. Water is added to carbon-sulphonated and filtered. The residue was washed up with water until $\mathrm{SO}_{4}{ }^{2-}$ ions are not detected in the filtrate.

\section{Biodiesel Synthesis with Carbon- $\mathrm{H}_{2} \mathrm{SO}_{4}$}

30.01 grams of Jatropha oil is put into a three-neck flask reflux and then 3.07 grams of carbon and 28.42 grams of methanol were added. Reflux was done at temperature $\pm 60^{\circ} \mathrm{C}$. After 6 hours, $2 \mathrm{~mL}$ of sulfuric acid; $\mathrm{H}_{2} \mathrm{SO}_{4}$ were added to the flask and reflux was continued. The mixture was separated by centrifugation at $\pm 3000 \mathrm{rpm}$.

\section{Biodiesel Synthesis with $\mathrm{H}_{2} \mathrm{SO}_{4}$}

29.32 grams of Jatropha oil is put into a three-neck flask reflux and then $2 \mathrm{~mL}$ of concentrated sulfuric acid and 9.6 grams of methanol were added. Reflux was done at temperature $\pm 60^{\circ} \mathrm{C}$. The mixture was separated by centrifugation at $\pm 3000 \mathrm{rpm}$.

\section{Characterization}

Density

The density is determined by weighing the empty pycnometer with an analytical balance and recorded weight, then synthesized substances are filled into the pycnometer and weighed, the weight of pycnometer containing synthesized substances were also recorded. Density measurements are also performed on the Jatropha oil for comparison.

Viscosity

The viscosity of Jatropha oil and the product were measured using Ostwald viscometer. Samples are transferred into the Ostwald viscometer tube and note the time required for the sample to flow from the upper to the lower limit mark.

\section{Refractive index}

Refractive index is determined using an Abbe refractometer. Determination of the refractive index of the sample was done by dripping synthesis results in the refractometer prism. Refractive index reading is made during light-dark separation line at the crosspositioning of the observation lens. Measurement of the refractive index was also conducted on Jatropha oil as a comparison.

\section{GC-MS Identification}

The results of GC-MS is used to identify the components of Jatropha oil methyl ester, as well as provide information and molecular structure of each molecular weight components of Jatropha oil methyl ester and its fragmentation.

\section{RESULT AND DISCUSSION \\ Carbon Preparation}

After heating for 17 hours, the sugar was obtained as a shiny brownish-black solid (Figure 2). The color changing from white sugar to brownish black (furnace result) is due to pyrolysis or decomposition of sugar (sucrose, $\mathrm{C}_{12} \mathrm{H}_{22} \mathrm{O}_{11}$ ) by heat. The black hue is the color of carbon, while the brownish black hue indicated that the product is not pure carbon. The 
result was put into a beaker, added concentrated sulfuric acid, and heated at $\pm 150{ }^{\circ} \mathrm{C}$ for 6 hours. After adding the concentrated sulfuric acid, the colorless solution turns into a brown suspension that becomes darker after heating. This change indicated that the reaction or interaction between sulfuric acid and sugar pyrolysis had been occured. After cooling down to room temperature, the blackish brown mixture was obtained. The mixture was filtered and the residue was washed with water until the $\mathrm{SO}_{4}{ }^{2-}$ ions were not detected in the filtrate. After drying at $60{ }^{\circ} \mathrm{C}$, a shiny black powder was obtained (Figure 3).

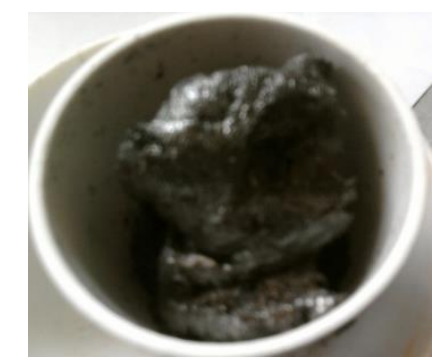

Figure 2. The result of heated sugar

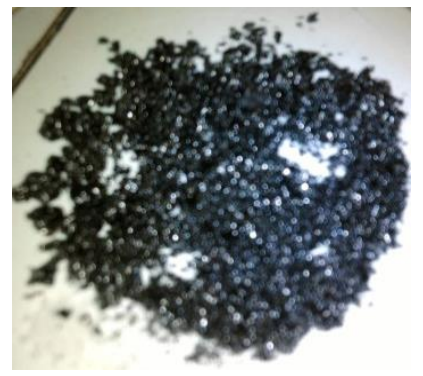

Figure 3. The result of sulfonated carbon

In this study, the pyrolysis of sugar was not performed under $\mathrm{N}_{2}$ flow. After the carbon sulphonation was used to catalysis the trans-esterification reaction, evidently it can't run the reaction. Mohammed et al (2015) explain that nitrogen flow in the pyrolisis process give effect for biofuel production. It can be concluded that the presence of $\mathrm{N}_{2}$ flow in the pyrolysis of sugar affects the results of pyrolysis. Accordance with Mo et al (2008) that reported about the use of sulfonic acid-containing catalysts on the esterification of free fatty acids with methanol. The catalyst was maked by pyrolization of sugars in nitrogen atmosphere. The sugar pyrolysis can't to be sulphonated, so it can be said that is a carbon.

\section{Biodiesel Synthesis with Carbon- $\mathrm{H}_{2} \mathrm{SO}_{4}$}

The result formed had three layers: the yellow upper layer was predicted as methyl ester, the middle layer was glycerol and the black bottom layer is carbon (Figure 4). The top layer is thought to be methyl esters and then purified. The characterization and identification were done to ensure that the results of the reaction with carbon- $\mathrm{H}_{2} \mathrm{SO}_{4}$ is methyl ester. 


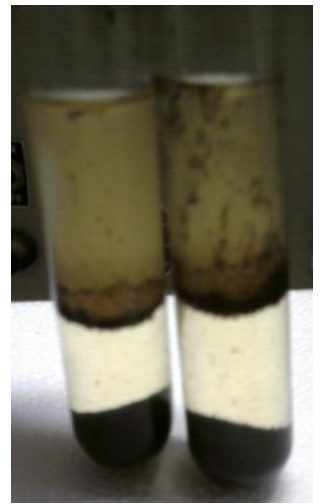

Figure 4. The result of biodiesel synthesized with carbon- $\mathrm{H}_{2} \mathrm{SO}_{4}$

\section{Biodiesel Synthesis with $\mathrm{H}_{2} \mathrm{SO}_{4}$}

Sulfuric acid catalyst is a catalyst that is commonly used in the synthesis of biodiesel. The result formed had two layers of brownish yellow top layer allegedly methyl ester and the undercoat was glycerol (Figure 5). The top layer is thought to be methyl ester and then purified. The characterization and identification were done to ensure that the result of the reaction with sulfuric acid catalyst is methyl ester.

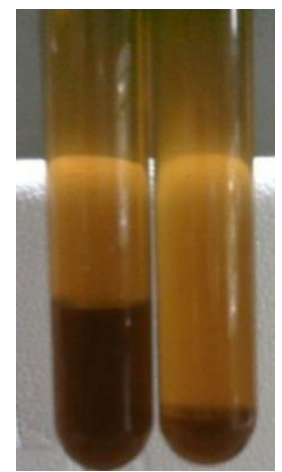

Figure 5. The result of biodiesel synthesized with $\mathrm{H}_{2} \mathrm{SO}_{4}$

\section{Characterization}

Density, viscosity and refractive index are listed in Table 1, Table 2 and Table 3.

Table 1. Density

\begin{tabular}{ll}
\hline Sample & $\begin{array}{l}\text { Density } \\
(\mathbf{g} / \mathbf{m L})\end{array}$ \\
\hline Jatropha oil & 0,903 \\
Synthesis with carbon- $\mathrm{H}_{2} \mathrm{SO}_{4}$ & 0,889 \\
Synthesis with $\mathrm{H}_{2} \mathrm{SO}_{4}$ & 0,882 \\
\hline
\end{tabular}


Table 2. Viscosity

\begin{tabular}{ll}
\hline Sample & $\begin{array}{l}\text { Viscosity } \\
\text { (cSt) }\end{array}$ \\
\hline Jatropha oil & 46,13 \\
Synthesis with carbon- $\mathrm{H}_{2} \mathrm{SO}_{4}$ & 24,59 \\
Synthesis with $\mathrm{H}_{2} \mathrm{SO}_{4}$ & 11,70 \\
\hline
\end{tabular}

Table 3. Refractive index

\begin{tabular}{ll}
\hline Sample & $\begin{array}{l}\text { Refractive } \\
\text { index }\end{array}$ \\
\hline Jatropha oil & 1,466 \\
Synthesis with carbon- $\mathrm{H}_{2} \mathrm{SO}_{4}$ & 1,462 \\
Synthesis with $\mathrm{H}_{2} \mathrm{SO}_{4}$ & 1,456 \\
\hline
\end{tabular}

Based on the characterization results of density, viscosity and refractive index, it can be seen that the result of the synthesized product was a methyl ester. The characterization results showed that the catalyst synthesized carbon- $\mathrm{H}_{2} \mathrm{SO}_{4}$ has a density, viscosity and refractive index higher than synthesized with sulfuric acid catalyst. This difference is caused by the difference of methyl ester content. To strengthen this prediction, GC-MS identification was done.

From the analysis of the mass spectrum in the GC-MS chromatogram, there were 4 major components. The result of synthesis using carbon- $\mathrm{H}_{2} \mathrm{SO}_{4}$ contains methyl ester, that is methyl palmitoleic (1), methyl palmitate (2), methyl linoleate (3) and methyl stearate (4).<smiles>CCCCCCCCCCCCCCCCCCCC</smiles>

(1)

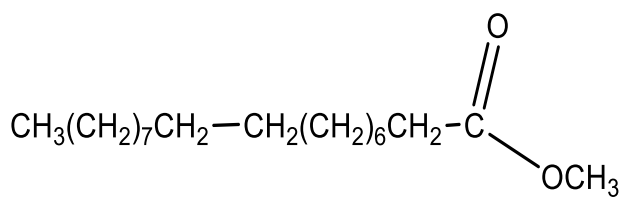

(3)<smiles>CCCCCCCCCCCCCCCCCCCCCCCC</smiles>

(2)

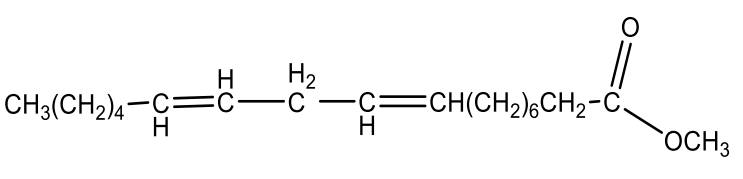

(4)

The results of the synthesis using sulfuric acid which contains methyl palmitoleic (1), methyl palmitate (2), methyl linoleate (3) and methyl oleate (4). 
<smiles>CCCCCCCCCCCCCCCCCC</smiles>

(1)

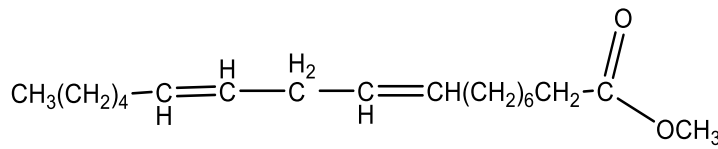

(3)<smiles>CCCCCCCCCCCCCCCCCCCCCCCCCC</smiles>

(2)<smiles>CCCCCCCCCCCCCCCCCCCCCCC</smiles>

(4)

GC-MS identification reinforced he product obtained using carbon- $\mathrm{H}_{2} \mathrm{SO}_{4}$ and with sulfuric acid catalysts were methyl ester. The product obtained using carbon- $\mathrm{H}_{2} \mathrm{SO}_{4}$ contains different methyl esters and hence the density, viscosity and refractive index were different from the one obtained using sulfuric acid catalyst.

The major difference in the components of methyl ester that was synthesized using carbon- $\mathrm{H}_{2} \mathrm{SO}_{4}$ and methyl ester that was synthesized using sulfuric acid, namely methyl stearate and methyl oleate because a chain reaction, unsaturated methyl oleate changes become saturated methyl stearate. The changes is possible because of the carbon, so it can be said that the carbon affects the reaction.

Physically,Jatropha oil methyl ester synthesized using carbon- $\mathrm{H}_{2} \mathrm{SO}_{4}$ forms a yellow and a colorless layer while Jatropha oil methyl ester synthesized using sulfuric acid catalyst forms a layer of brownish yellow and another reddish-brown layer. The pale color of the solution obtained using carbon- $\mathrm{H}_{2} \mathrm{SO}_{4}$ is due to the adsorption of dye by the carbon.

\section{CONCLUSION}

Carbon affected biodiesel synthesis. Transesterification reaction of Jatropha oil and methanol with carbon- $\mathrm{H}_{2} \mathrm{SO}_{4}$ produced methyl ester that has a density of $0.889 \mathrm{~g} / \mathrm{mL}$, a viscosity of $24.59 \mathrm{cSt}$, and a refractive index of 1.464. Methyl esters obtained from the transesterification reaction of Jatropha oil with methanol and sulfuric acid has density of $0.882 \mathrm{~g} / \mathrm{mL}$, a vis $11.70 \mathrm{cSt}$ viscosity and refractive index of 1.458 .

\section{REFERENCES}

Fukuda, H., Kondo, A. \& Noda, H. (2001). Biodiesel Fuel Production by Transesterification of Oils. Journal of Bioscience and Bioengineering, 92 (5), 405-416.

Lotero, E., Liu, Lopez, D. E., Suwannakarn, K., Bruce, D. A., \& Goowin, J. G. (2005). Synthesis of Biodiesel via Acid Catalysis. Ind. Eng. Chem. Res, 44, 5353-5363 
Mo, X., Lopez, D. E., Suwannkarn, K., Liu, Y., Lotero, E., Goodwin, J. J. G., \& Lu, C. (2008). Activation and deactivation characteristics of sulfonated carbon catalysts. Journal of Catalyst, 254(2), 332-338

Mohammed, I., Y., Abakr, Y., A., Kazi, F., K., Yusuf, S., Alshareef, I., \& Chin, S., A. (2015). Pyrolysis of Napier Grass in a Fixed Bed Reactor: Effect of Operating Conditions on Product Yields and Characteristics. BioResources, 10(4), 6457-6478. DOI: 10.15376/biores.10.4.6457-6478.

Okamura, M., Takagaki, A., Toda, M., Kondo, J. N., Domen, K., Tatsumi, T., Hara, M., \& Hayashi, S. (2006). Acid-Catalyzed Reaction on Flexible Polycyclic Aromatik Carbon in Amorphous Carbon. Chem. Mater, 18, 3030-3045.

Ramírez-Arias, A. M., Giraldo, L., \& Moreno-Piraján, J. C. (2017). Biodiesel Synthesis: Use of Activated Carbon as Support of the Catalysts. Biorefining of Biomass to Biofuels, 117-152. doi:10.1007/978-3-319-67678-4_5

Santos, E.M., Teixeira, A.P. de C., da Silva, F.G., Cibaka, T.E., Araújo, M.H., Oliveira, W.X.C., Medeiros, F., Brasil, A.N., de Oliveira, L.S., Lago, R.M. (2015). New heterogeneous catalyst for the esterification of fatty acid produced by surface aromatization/sulfonation of oilseed cake. Fuel. 150, $408-414$.

Sherbiny, S. A. E., Refaat, A. A., Sheltawy, S. T. E. (2010). Production of biodiesel using the microwave technique. Journal of Advanced Research, 1(4): 309-314. DOI: doi.org/10.1016/j.jare.2010.07.003

Shu, Q., Zhang, Q., Xu, G., Nawaz, Z., Wang, D., Wang, J. (2009). Synthesis of biodiesel from cottonseed oil and methanol using a carbon-based solid acid catalyst. Fuel Processing Technology, 90(7-8), 1002-1008

Subhedar, P. B., \& Gogate, P. R. (2016). Ultrasound assisted intensification of biodiesel production using enzymatic interesterification. J. Ultsonch, 29: 67-75. DOI: 10.1016/j.ultsonch.2015.09.006

Tamborini, L.H., Militello, M.P., Balach, J., Moyano, J.M., Barbero, C.A., Acevedo, D.F. (2019). Application of sulfonated nanoporous carbons as acid catalysts for Fischer esterification reactions. Arab. J. Chem. 12, 3172-3182.

Thushari, I., Babel, S. (2018). Sustainable utilization of waste palm oil and sulfonated carbon catalyst derived from coconut meal residue for biodiesel production. Bioresour. Technol. 248, 199-203.

Toda, M., Takagaki, A., Okamura, M., Kondo, J. N., Hayashi, S., Domen, K. \& Hara, M. (2005). Biodiesel Made with Sugar Catalyst. Nature, 438.

Vasudevan, P. T \& Briggs, M. (2008) Biodiesel Production Current State of the Art and Challenges. J Ind Microbiol Biotechnol, 35, 421-430.

Al-Kimia|Volume 8 Nomor 120208 
Zhang, F., Tian, X., Shah, M., Yang, W. (2017). Synthesis of magnetic carbonaceous acids derived from hydrolysates of Jatropha hulls for catalytic biodiesel production. RSC Adv. 7, 11403-11413.

Zong Min-Hua, Duan Zhang-Qun, Lou Wen-You, Smith, T. J. \& Wu, H. (2007). Preparation of a Sugar Catalyst and Its Use for Highly Efficient Production of Biodiesel. Green Chem, 9, 434-437. 